\title{
The Comparison of Using Words Between Enlightenment Online and Vietnamese Buddhist Temple
}

\author{
Nguyen Van Thao \\ Faculty of Philology, Hanoi Pedagogical University 2, Vietnam \\ nguyenvanthao@hpu2.edu.vn
}

\begin{abstract}
Keywords:

Buddhist,

Jargon,

Enlightenment Online,

Vietnam Buddhist

Temple.

Vietnamese vocabulary is divided by different criteria, such as: word classes by origin; according to the scope of use; by using style and by positive and negative criteria, specifically, the native word class is the core class in Vietnamese vocabulary, which is a prop and plays a controlling role, controlling the activities of other word classes. Identifying a word as a native word is no easy task. Because Vietnamese has a common origin with Mon - Khmer languages. Therefore, there are words that still share common words. Finding the exact origin is extremely difficult, even for linguistic historians. In addition, the scope of words usage, the southern Buddhist press is heavily influenced by the Southern dialect, this is understandable because the writers (Buddhist reporters) often come from the South and one more thing is written for southern readers. In contrast, the current use of Buddhist jargon requires an exchange, that is: speaking of the Buddhist press language, it is impossible not to mention the word class (jargon) that has its own particularity. Buddhist jargon plays a tremendous role in preserving and promoting the values of Buddhism. It is inconceivable if the Buddhist language did not have these jargon.
\end{abstract}

Article History:

Received: 27-06-2018

Revised : 19-08-2018

Accepted: 28-08-2018

Online : $30-08-2018$

\author{
This is an open access article under the CC-BY-SA license \\ Crossret \\ https://doi.org/10.31764/ijeca.v1i2.2132
}

\section{A. INTRODUCTION}

Language is a special signaling system, a tool of thinking and communication. Through languages, people can exchange feelings, aspirations and beliefs with each other. In Buddhism, language is the means of mission, the soul of dharma protection.

In order to live with other religious and belief communities, Vietnamese Buddhism has chosen to live a "good life, good religion" that has actually gone into social activities such as: Relief, free medical examination and treatment for the poor and helping the unfortunate, ... By Buddhism the concept: "Although building nine levels of Buddha tower, not as a blessing for a person". Therefore, the beauty of life does not stop at the beauty of culture, social morality, but also the faith towards the good things towards the values of truth-kind-beauty. Therefore, the spread and information about Buddhism is a very important task of the Buddhist press.

The press language includes the language of radio and television, the language of advertising, marketing, etc. Meanwhile, the specialty of the press is to convey information to the readers, to the audience. Therefore, the press language must be standard, accurate and easy to absorb for 
the perceivers. The language of Buddhist press is no exception to that rule. However, no one has studied the comparison of using words between Enlightenment online and Vietnam Buddhist Temple in Vietnam. Therefore, it can be said that this is necessary and urgent, in order to show how to use the distinct and unique language of Vietnamese Buddhist press in today's integration period.

\section{B. METHODS}

The scope of our research is articles published in 4 months from December 2016 to march 2017 and each month 5 issues on two online newspapers of Vietnamese Buddhist Press, one in the North and one in the South of Vietnam: Vietnam Buddhist Temple (https://phatgiao.org.vn/emagazine/) and Enlightenment online (http://giacngo.vn/). After reading all the articles have mentioned, we find out and collect all the words as we research, from then statistic and separate those in to their classes and count the rate then compare the rate of them. Finally, discuss about classes and concrete samples for more clearly

This method is used to describe the linguistic characteristics of Buddhist press, so that it can identify the specific characteristics of the Buddhist language in the current media. Systemize different language usage of each newspaper page and between newspapers. These tactics helps us to statistic and classify the number and frequency of linguistic phenomena that are specific to Buddhist press. To compare the use of words in the Southern Buddhist press with the Northern Buddhist press in Vietnam. In brief, these methods and calligraphies applied for analyzing the data on the scope of Buddhism press.

\section{RESULT AND DISCUSSION}

\section{The scope of usage}

Gaillard in the book of Journalists (Gaillard P., 2003), presented the role of journalists and news agencies in reporting. According to him, journalists must choose the event according to the following criteria: Hot news: The public is always waiting for the answer to the question: "is there anything new?". Meaning: Applies to the event and its impact scope. For example: Dog biting people is normal; but people biting dog is unusual, the subject of journalism; Concern: To what extent is the significance and topicality of the news to the public?

In the book Modern Journalists (Group, 2005), the author presented the nature of news in the 21st century, in order to meet the readers' demand, information must have the following properties: interaction, diversity, relevance, eye-catching form, dense information, depth.

In Vietnam, the earliest researches on journalism must include a number of articles published in newspapers and magazines from the first half of the twentieth century, but it is impossible not to mention Ham's "Vietnamese history of literary" (1941) cited the effect of the press as "information in the country and issuing government orders, helping to establish the national culture, incorporating into Vietnamese many new nouns of philosophy and science, helping to unify the voice of three states " (D.Q, 1941).

The language redaction of books and newspapers (Bau N. T., 2002) recognized the phonetic level, vocabulary, grammar and gave editorial rules at each linguistic level. Or in Press Language, Hao (Hao V. Q, 2001) gave the general characteristics of the standard language of the press and the characteristics of the style of political language, style of scientific 
language, style of administrative language. At the same time, presenting private names, headlines, scientific terms (Hao V. Q, 2001).

There are also a number of journalism magazines which are specialized journals of the Journalists Association of Ho Chi Minh City has a wide range of journalism topics that have highlighted many issues to keep in mind in the way language is used in the press.

When referring to the nature of press information, in addition to confirming the role of the media language, the authors proposed a number of operational skills such as choosing news events, article structure and language standard in journalism.

Some books, dissertations on journalism's language can be listed, including: Some issues of using language in the press (H., 2003); Press bodies Các thể ký báo chí; How to write a newspaper? (Duc, 2000); Discussion on style of journalism (Huong. D, 2004); Journalism language of Saigon-Ho Chi Minh City (T.T, 2011); Journalism language (Nien. N.T, 2003); Basic rationale of media journalism (Son. D.X, Huong. D.V, 2004) and some other related studies can be listed as: Dung. H. V. (Dung. H.V, 2013), Duc. H.M. (Duc. H.M, 1996), Phuong. D. (Phuong. D, 2000).

History of Buddhist linguistic research is not much, only a few studies such as: Vietnam Buddhist Press from the point of view of media theory (Thanh. M, 2010); Religion into modern life; Buddhist journalism in Vietnam- Current situation and issues (Hanh. L.T.H, 2010); Buddhism is related to the life of human life (Hao V. Q, 2001); The introduction of Buddhism into our country and its influence in the 10-14 century (Huy. L.T, 2010) etc.

Table 1. Statistical Table of The Number of Dialect and Jargon

\begin{tabular}{|c|c|c|c|c|c|}
\hline No & Newspaper name & Dialect & Rate & Jargon & Rate \\
\hline 1 & Vietnamese Buddhist Temple & 246 & 9.99 & 3921 & 50.8 \\
\hline 2 & Enlightenment online & 2491 & 90.01 & 3792 & 49.2 \\
\hline & Total & $\mathbf{2 7 3 7}$ & $\mathbf{1 0 0}$ & $\mathbf{7 7 1 3}$ & $\mathbf{1 0 0}$ \\
\hline
\end{tabular}

Vietnamese Temple newspaper uses the Northern dialect with very low numbers with 246 words accounting for 9.99\%, while the Enlightenment page uses the Southern dialect with 2491 words, accounting for $90.01 \%$. Total of two newspapers use 2737 words belonging to the Northern and Southern dialect. Thus, it can be seen that the Northern Buddhist press is strongly influenced by the common language, so it uses very little Northern dialect. In contrast, the southern Buddhist press is heavily influenced by the Southern dialect, so it has used the Southern dialect in such large numbers of articles. This is understandable because the writers (Buddhist reporters) often come from the South and one more thing is written for southern readers should use the southern dialect.

In contrast to the usage of the dialect of the two newspapers, the number and frequency of using Buddhist jargon both in the South and the North are equivalent to a total of 7713 Buddhist jargon. In which, the Vietnam Buddhist Temple newspaper uses 3921 jargon, accounting for $50.8 \%$ and Enlightenment Newspaper uses 3792 jargon with $49.2 \%$. Thus, whether the press is in the North or the South, the use of jargon does not differ. This is true of the use of Buddhist jargon in general and the Buddhist media in particular.

The language of Buddhist press is also a component of Vietnamese, the Buddhist press is adapted to different audiences. The Buddhist press in North of Vietnam mainly uses the common words and the Buddhist press in the South of Vietnam uses the Southern dialect. According to us this is suitable with the regular of society and language. Therefore, it is not much to discuss the use of dialects in the Southern Buddhist press. In contrast, the current use 
of Buddhist jargon requires an exchange, that is: speaking of the Buddhist press language, it is impossible not to mention the word class (jargon) that has its own particularity. Buddhist jargon plays a tremendous role in preserving and promoting the values of Buddhism. It is inconceivable if the Buddhist language did not have these jargon. However, there is a current paradox in the use of words in Buddhist media with the developmental orientation of Buddhism. It is not only conveying the thoughts and teachings of Buddhism to the monks and nuns, but also to convey to the various classes of people in Vietnamese society in order to educate the ideology and entice readers to believe and follow Buddhism. But Buddhist jargon is both strength and a barrier to this goal. Not everyone can understand the Buddhist jargon so the effectiveness of the communication is significantly limited. On the contrary, if Buddhism does not use jargon, it will face a decline in its own identity, especially losing the mysticism that religion must have. Therefore, Buddhism may need to adjust the use of jargon and common words in a harmonious manner, both preserving its identity and possibly not confusing the readers. Thus, the Buddhist media will achieve its goals.

\section{Vocabulary characteristics in terms of origin}

The Vietnamese vocabulary system is divided by many different criteria, which can be divided into criteria such as: word classes by origin; according to the scope of use; by using style and by positive and negative criteria, specifically, the native word class is the core class in Vietnamese vocabulary, which is a prop and plays a controlling role, controlling the activities of other word classes. Identifying a word as a native word is no easy task. Because Vietnamese has a common origin with Mon - Khmer languages, the closest language to Vietnamese is Muong. Therefore, there are words that still share common words. Finding the exact origin is extremely difficult, even for linguistic historians.

Table 2. Statistical table of the number of borrowed words

\begin{tabular}{|c|c|c|c|}
\hline No & Origin borrowed & Quantity & Rate \\
\hline 1 & India & 25 & 0.6 \\
\hline 2 & Accient China & 2331 & 55.1 \\
\hline \multirow[t]{2}{*}{3} & Indo Europe & 1873 & 44.3 \\
\hline & Total & 4229 & 100 \\
\hline
\end{tabular}

We have a total of 4229 words borrowed from three different sources. The words imported into Vietnam from India is only 25 words with $0.6 \%$, the most borrowed from the Chinese, that has 2331 words, accounting for 55.1\%. Ranked second in terms of number and borrowing rate is the Indo-European words with 1873 words, accounting for $44.3 \%$. It can be seen that, Vietnamese people borrow words with origin of Chinese with the largest number of borrowed words. This shows that the influence of Chinese culture and language on Vietnamese people is very long-term and strongly influences the use of words. On the other hand, Vietnam has just opened, interacted and contacted with Western countries (Indo-European languages) for only a few recent decades, but has borrowed a huge number of words. With this trend, the Indo-European words will penetrate more and more quickly in the coming period. This shows two aspects, the ability of integrating into the world relatively strong, gradually catching up with the pace of human development. However, the rapid integration without control leads to confusion in the use of language in particular and possibly in other issues of social life. Besides the two big loans mentioned above, it is impossible not to mention the words of Indian origin, the origin of Buddhism. However, it must be acknowledged that Buddhism's introduction 
directly into Vietnam has left a rather faint impression, which through the words left, also clearly shows that.

Thus, the use of borrowed words has shown the integration in both the past and the present of Vietnamese people. Previously integrating with religion and commerce with Indians, we borrowed the Indian words through indoctrination (Buddhism). We not only integrate with the Indians but also interact with the Chinese people through a long history, receive Chinese culture, trade with the Chinese people, learn from the wars with the China. Especially, the China colonized for over a thousand years. Therefore, Buddhism also came from these contact paths into our Vietname. At the same time, the borrowed words thus penetrate Vietnamese vocabulary. It was before, but today, we have been deeply integrated with the outside world in all areas of life. From that integration, their language also translates into Vietnamese. This is indispensable and completely true to the regular of perception and the language. However, borrowing needs to be organized and orderly. Unfortunately, we do not have a plan or a specific, consistent orientation to receive these new language elements, that resulting in widespread and inconsistent borrowing and use, being distorted, affecting the development of Vietnamese, losing the purity of Vietnamese language.

\section{CONCLUSION AND SUGGESTIONS}

The Northern Buddhist press is strongly influenced by the common language, so it uses very little Northern dialect. In contrast, the southern Buddhist press is heavily influenced by the Southern dialect, so it has used the Southern dialect in such large numbers of articles. This is understandable because the writers (Buddhist reporters) often come from the South and one more thing is written for southern readers should use the southern dialect. And the use of jargon does not differ so much between press in the North and the South. This is true of the use of Buddhist jargon in general and the Buddhist media in particular.

About the words origin, Vietnamese people borrow words with origin of Chinese with largest number of borrowed words. This shows that the influence of Chinese culture and language on Vietnamese people is very long-term and strongly influences the use of words. On the other hand, Vietnam has just opened, interacted and contacted with Western countries (Indo-European languages) for only a few recent decades, but has borrowed a huge number of words. With this trend, the Indo-European words will penetrate more and more quickly in the coming period. This shows two aspects, the ability of integrating into the world relatively strong, gradually catching up with the pace of human development.

\section{REFERENCES}

Bau N. T. (2002). The Language Redaction of Books and Newspapers. Social Science.

D.Q, H. (1941). Vietnamese History of Literacy. Center of Educational Facilities of Ministry of Education.

Duc. H.M. (1996). Journalism - Theoretical and practical issues. Hanoi Education.

Duc, D. (2000). How to write a newspaper. Culture and information.

Dung. H.V. (2013). The characterstics of Hoa Hoc Tro Newspaper. University of Social Sciences and Humanities.

Gaillard P. (2003). Journalists. Information.

Group, T. M. (2005). Modern Journalists. Youth.

H., A. (2003). Some Issues of Using Language in The Press. Lao Dong.

Hanh. L.T.H. (2010). Buddhist journalism in Vietnam- Current situation and issues. Hanoi University of Social Sciences and Humanities. 


\section{IJECA (International Journal of Education and Curriculum Application)}

Vol. 1, No. 2, August 2018, pp. 19-24

Hao V. Q. (2001). Press Language. National University.

Huong. D. (2004). Discussion on style of journalism. Journal of Journalists.

Huy. L.T. (2010). The introduction of Buddhism into our country and its influence in the 10-14 century. Buddhists Today.

Nien. N.T. (2003). Journalism language. Dong Nai Synthetic.

Phuong. D. (2000). Memoir about journalism. Ethnic Culture.

Son. D.X, Huong. D.V, Q. T. (2004). Basic rationale of media journalism. National University.

T.T, N. (2011). Journalism language of Saigon-Ho Chi Minh City. University of Education.

Thanh. M. (2010). Vietnamese Buddhist Press from the point of view of media theory. Phat Luan Magazine. 